\title{
A Computer-Based Glucose Management System Reduces the Incidence of Forgotten Glucose Measurements: A Retrospective Observational Study
}

\author{
Tsuyoshi Okura (D) Kei Teramoto - Rie Koshitani · Yohei Fujioka • \\ Yusuke Endo · Masaru Ueki · Masahiko Kato · Shin-ichi Taniguchi • \\ Hiroshi Kondo $\cdot$ Kazuhiro Yamamoto
}

Received: February 23, 2018 / Published online: April 17, 2018

(C) The Author(s) 2018

\begin{abstract}
Introduction: Frequent glucose measurements are needed for good blood glucose control in hospitals; however, this requirement means that measurements can be forgotten. We developed a novel glucose management system using an iPod ${ }^{\circledR}$ and electronic health records.

Methods: A time schedule system for glucose measurement was developed using point-of-
\end{abstract}

Enhanced digital features To view enhanced digital features for this article go to https://doi.org/10.6084/ m9.figshare.6097400.

T. Okura $(\bowtie) \cdot$ Y. Fujioka $\cdot$ M. Kato $\cdot$ K. Yamamoto Division of Cardiovascular Medicine, Endocrinology and Metabolism, Department of Molecular Medicine and Therapeutics, Tottori University Faculty of Medicine, Yonago, Tottori, Japan e-mail: ohkura@med.tottori-u.ac.jp

K. Teramoto $\cdot$ H. Kondo

Division of Medical Informatics, Tottori University Hospital, Yonago, Tottori, Japan

R. Koshitani

Division of Nursing, Tottori University Hospital,

Yonago, Tottori, Japan

Y. Endo $\cdot$ M. Ueki

Advanced Medicine, Innovation and Clinical

Research Center, Tottori University Hospital,

Yonago, Tottori, Japan

S. Taniguchi

Department of Regional Medicine, Tottori

University Faculty of Medicine, Yonago, Tottori, Japan care testing, an $\mathrm{iPod}^{\circledR}$, and electronic health records. The system contains the glucose measurement schedule and an alarm sounds if a measurement is forgotten. The number of times measurements were forgotten was analyzed.

Results: Approximately 7000 glucose measurements were recorded per month. Before implementation of the system, the average number of times measurements were forgotten was 4.8 times per month. This significantly decreased to 2.6 times per month after the system started. We also analyzed the incidence of forgotten glucose measurements as a proportion of the total number of measurements for each period and found a significant difference between the two 9-month periods $(43 / 64,049-24 / 65,870$, $P=0.014$, chi-squared test).

Conclusions: This computer-based blood glucose monitoring system is useful for the management of glucose monitoring in hospitals.

Funding: Johnson \& Johnson Japan.

Keywords: Computer informatics; Glucose monitoring; In-hospital care; Risk management

\section{INTRODUCTION}

Perioperative blood glucose control is important for patients with diabetes [1]. Hyperglycemia induces perioperative infection and a delay in wound healing [2], and hypoglycemia increases the risk for perioperative death [3]. 
Frequent measurement of glucose is needed for good blood glucose control. Glucose monitoring is recommended to be performed before meals in a patient who is eating meals, and every $4-6 \mathrm{~h}$ in a patient who is not eating [1]. More frequent blood glucose testing is required for patients receiving insulin intravenously, from every $30 \mathrm{~min}$ to every $2 \mathrm{~h}$. However, the requirement for frequent measurement tends to result in people forgetting to take measurements when required. Further, hand-written reports can result in transcription errors [4]. A novel strategy is needed to improve the measurement and recording of blood glucose levels. One strategy aimed at resolving these problems is the Computerized Physician Order Entry, which has been designed to prevent medication-related errors $[1,5]$. The US Health Information Technology for Economic and Clinical Health Act recommends the use of the Computerized Physician Order Entry. A computerbased insulin ordering system improved the glycemic control of patients without increasing hypoglycemia [6].

We hypothesized that a computer-based glucose monitoring system would be effective for the management of glucose measurements in hospitals. To this end, we developed a novel glucose monitoring system using an iPod ${ }^{\circledR}$ and electronic health records. We previously reported that the novel system reduced delays in measurements [7]. In the current study, we evaluated the number of times that glucose measurements were forgotten before and after the system was introduced, and analyzed information contained within incident reports.

\section{METHODS}

\section{Study Design}

This study was a retrospective observational study of patients admitted to our hospital as usual. The recruited patients were admitted for operations, infection, glycemic control, and other reasons. The data for this study were extracted from the records in the electronic medical record system, which consisted of blood glucose levels of inpatients with diabetes mellitus who were admitted to between January 1, 2014 and September 30, 2016.

This study was performed at Tottori University Hospital between 2014 and 2016. The glucose monitoring system was initially introduced at our hospital in November 2014, and was fully operational throughout the hospital by November 2015. We evaluated the number of times that glucose measurements were forgotten in a 9-month period before the system was introduced (January to September 2014) and a 9-month period after the system was fully operational (January to September 2016). This study included all wards of the hospital.

Compliance with Ethics Guidelines This study was conducted in accordance with the 1964 Declaration of Helsinki and its later amendments, and was approved by the Ethics Committee of the Faculty of Medicine, Tottori University (Approval No. 1611A136). Informed consent was obtained from all individual participants included in the study by the opt-out method. As this study was a retrospective observational study, we did not register it as a clinical trial.

\section{Glucose Management System}

The details of the glucose management system have been described in a previous report [7]. Glucose measurements were performed using point-of-care testing meters (OneTouch $^{\circledR}$ Verio $^{\text {TM }}$ Plus; Johnson \& Johnson Japan, Tokyo, Japan), with glucose data being immediately transferred to an $\mathrm{iPod}^{\circledR}$ (Apple, Cupertino, CA, USA) and an electronic medical record system (IBM Japan; Tokyo, Japan) in real time. The glucose management schedule is managed by an application in the $\mathrm{iPod}^{\circledR}$ and is based on orders in the electronic medical record system. If a glucose measurement is forgotten, an alert is displayed on the $\mathrm{iPod}^{\circledR}$ screen and an alarm sounds.

\section{Data Collection}

We collected data on total glucose measurements from orders in the electronic medical 
record system and the incidence of forgotten glucose measurements from incident reports. Examination of incident reports was permitted by the risk management committee at our hospital. Prior to the implementation of the system, an analog timer was used as a reminder to check blood glucose. We defined the causes of missing blood glucose measurements as missed worksheets, heavy workload on nurses, doctors not using the ordering system, did not use an analog timer, did not use the application, could not operate the new system, and other.

\section{Statistical Analysis}

Data are expressed as mean \pm standard deviation. The difference between the average number of incidents before and after the system was implemented was analyzed using unpaired $t$ tests. The chi-squared test was used for categorical comparisons of data. A $P$ value less than 0.05 was considered statistically significant. SPSS software (ver. 24.0; IBM Corp., Armonk, NY, USA) was used for all analyses.

\section{RESULTS}

There were 64,049 glucose measurements taken in the 9-month period before and 65,870 taken in the 9-month period after the system was started (Table 1). The average number of glucose measurements was $7318.8 \pm 655.5$ per month before the system started and $7116.5 \pm 626.3$ after the system started. There was no significant difference in the average number of measurements between the two 9-month periods $(P=0.31$, unpaired $t$ test).

There were 43 incidents of forgotten glucose measurements before the system started and 24 after the system started in each 9-month period. The average number of times that glucose measurements were forgotten was $4.8 \pm 1.4$ times per month before the system started and $2.6 \pm 1.5$ times after the system started. There was a significant difference in the average number of forgotten measurements between the two 9 -month periods ( $P=0.003$, unpaired $t$ test).

We analyzed the incidence of forgotten glucose measurements as a proportion of the total number of measurements for each period and found a significant difference between the two 9-month periods $(P=0.014$, chi-squared test).

We analyzed the reasons for forgotten measurements and found that the most common reason before the system started was missed worksheets $(n=17)$. There were no incidents of missed worksheets after the system started. The second most common reason for forgotten measurements was human error because of the heavy workload on nurses $(n=9)$. This dropped to four incidents after the system started. The third most common reasons before the system started was that doctors were not using the ordering system $(n=5)$ and that an analog timer was not used $(n=5)$. The most common reason for forgotten glucose measurements after the system started was that the glucose management system was not used (did not use the application, $n=5$; did not use the ordering system, $n=4)$. There was no incident report of transcription errors in the study period.

Table 1 Number of times glucose measurements were forgotten

\begin{tabular}{lll}
\hline & Number of forgotten glucose measurements & Total number of glucose measurements \\
\hline Before system started & 43 in 9-month period & 64,049 in 9-month period \\
& Average $4.8 \pm 1.4$ per month & Average $7318.8 \pm 655.5$ per month \\
After system started & 24 in 9-month period & 65,870 in 9-month period \\
& Average $2.6 \pm 1.5$ per month & Average $7116.5 \pm 626.3$ per month \\
$P$ value (unpaired $t$ test) & 0.003 & 0.31 \\
\hline
\end{tabular}

Chi-squared test. $P$ value was 0.014 


\section{DISCUSSION}

In this study, we found that the computer-based glucose monitoring system significantly reduced the number of times that glucose measurements were forgotten. In particular, the number of times that measurements were forgotten because of missed worksheets dropped to zero. These results suggest that the computerbased glucose monitoring system is an effective tool for the management of glucose measurements in hospitals. The current study and past reports suggest that computer-based risk management systems are effective in reducing the number of incidents $[1,5,6]$.

It takes approximately $5 \mathrm{~min}$ for a caregiver to measure glucose levels using a blood sample, glucose meter, and test strip. It therefore takes more than $2 \mathrm{~h}$ per day for hourly monitoring by a caregiver [8]. Because human resources are limited, frequent glucose monitoring is difficult and a novel risk management system is needed. The system discussed in the current study may help to manage the risks associated with frequent glucose monitoring.

A recent study reported that a computerbased insulin ordering system reduced the number of insulin dosing errors when compared with a paper-based workflow management system [9]. However, in that study, the computer-based management system showed an increase in the number of missed glucose measurements compared with the paper-based management system. The authors suggest that the reason for this was that while a scroll wheel was used to enter blood glucose values, the main source of errors could have been that values were either incorrectly remembered or temporarily noted incorrectly during manual transfer. The absence of an instant automated transfer of glucose measurement data to Glu$\mathrm{coTab}^{\circledR}$ at point-of-care testing was noted as a potential risk. The authors described a way of providing blood glucose values in a timely manner and identified that direct automated transfer of blood glucose values at the point-ofcare can eliminate errors. On the basis of this report and our own study, we consider that realtime transfer and automated handling of glucose measurements are important for glucose management in hospitals.

Our study has some limitations. First, the study period was short and a longer period is needed to confirm the results. Incidents decreased throughout the study period; the mean incidence was 3.3 times/month in the first 6 months after the system started and 1.3 times/month in the last 3 months of the study period. However, as more experience with a system can be associated with carelessness, errors may still increase over a longer time frame. Second, the number of forgotten measurements was determined using incident reports. This makes it possible that incident times might not be exact. Third, while the number of forgotten measurements did reduce, they were not eliminated completely. When we analyzed the number of incidents after the system started, forgotten measurements still occurred when medical staff did not use the system. The glucose management system was used $80 \%$ of the time, meaning that it was not used $20 \%$ of the time. A higher use rate is needed. Lastly, we could not obtain incident information from other hospitals, so an external comparison of results was not possible.

\section{CONCLUSIONS}

The results of this study suggest that the computer-based glucose management system was effective for the management of glucose measurements at our hospital. The system significantly reduced the number of times glucose measurements were forgotten.

\section{ACKNOWLEDGEMENTS}

We thank the participants of the study.

Funding. This work was supported by Johnson \& Johnson Japan. Johnson \& Johnson Japan also provided funding for the journal's article processing charges and editorial assistance. All authors had full access to all of the data in this 
study and take complete responsibility for the integrity of the data and accuracy of the data analysis.

Editorial Assistance. We thank Mr. Yuichiro Tomita and Ms. Erika Matsui for their excellent technical assistance. We also thank Edanz Group (www.edanzediting.com/ac) for editing a draft of this manuscript. This editorial support was funded by Johnson \& Johnson Japan.

Authorship. All named authors meet the International Committee of Medical Journal Editors (ICMJE) criteria for authorship for this article, take responsibility for the integrity of the work as a whole, and have given their approval for this version to be published.

Authorship Contributions. Tsuyoshi Okura participated in the design of the study and performed the statistical analysis. Kei Teramoto, Rie Koshitani, and Yohei Fujioka collected the data. Yusuke Endo, Masaru Ueki, Masahiko Kato, Shin-ichi Taniguchi, Hiroshi Kondo, and Kazuhiro Yamamoto conceived the study, participated in its design and coordination, and helped draft the manuscript. All authors read and approved the final manuscript.

Disclosures. Tsuyoshi Okura, Kei Teramoto, Rie Koshitani, Yohei Fujioka, Yusuke Endo, Masaru Ueki, Masahiko Kato, Shin-ichi Taniguchi, Hiroshi Kondo, and Kazuhiro Yamamoto have nothing to declare.

Compliance with Ethics Guidelines. This study was conducted in accordance with the ethical standards of our institutional research committee and with the 1964 Declaration of Helsinki and its later amendments. Informed consent was obtained from all individual participants included in the study by the opt-out method.

Data Availability. The datasets generated during and/or analyzed during the current study are available from the corresponding author on reasonable request. This manuscript includes all the available data in this study.
Open Access. This article is distributed under the terms of the Creative Commons Attribution-NonCommercial 4.0 International License (http://creativecommons.org/licenses/ by-nc/4.0/), which permits any noncommercial use, distribution, and reproduction in any medium, provided you give appropriate credit to the original author(s) and the source, provide a link to the Creative Commons license, and indicate if changes were made.

\section{REFERENCES}

1. American Diabetes Association. Diabetes care in the hospital. Diabetes Care. 2016;39(Suppl 1):S99-104. https://doi.org/10.2337/dc16-S016.

2. van den Berghe G, Wouters P, Weekers F, et al. Intensive insulin therapy in critically ill patients. N Engl J Med. 2001;345:1359-67.

3. Finfer S, Chittock DR, Su SY-S, NICESUGAR Study Investigators, et al. Intensive versus conventional glucose control in critically ill patients. N Engl J Med. 2009;360:1283-97.

4. Institute of Medicine (US) Committee on Quality of Health Care in America. To err is human: building a safer health system. Washington, DC: National Academies Press; 1999.

5. Aspden P, Wolcott J, Bootman JL, Cronenwett LR, editors. Institute of medicine. Preventing medication errors. Washington, DC: National Academies Press; 2007.

6. Wexler DJ, Shrader P, Burns SM, Cagliero E. Effectiveness of a computerized insulin order template in general medical inpatients with type 2 diabetes: a cluster randomized trial. Diabetes Care. 2010;33:2181.

7. Teramoto K, Okura T, Koshitani R, et al. Development and evaluation of a blood glucose management system for reducing the delay in measurement. Stud Health Technol Inform. 2017;245:1058-62.

8. Joseph JI, Hipszer B, Mraovic B, Chervoneva I, Joseph $\mathrm{M}$, Grunwald Z. Clinical need for continuous glucose monitoring in the hospital. J Diabetes Sci Technol. 2009;3:1309-18.

9. Donsa K, Beck P, Höll B, et al. Impact of errors in paper-based and computerized diabetes management with decision support for hospitalized patients with type 2 diabetes. A post hoc analysis of a before and after study. Int J Med Inform. 2016;90:58-67. 